\title{
Mast cells in newly formed lining tissue during acute inflammation: a six day air pouch model in the mouse
}

\author{
Y M SIN, ${ }^{1}$ A D SEDGWICK, ${ }^{2}$ E P CHEA, ${ }^{1}$ AND D A WILLOUGHBY 3
}

From the ${ }^{1}$ Department of Zoology, National University of Singapore, Singapore 0511; the ${ }^{2}$ Department of Pharmacology, The Royal Veterinary College, Hatfield, Herts; and the ${ }^{3}$ Department of Experimental Pathology, St Bartholomews Hospital, West Smithfield, London

SUMmaRY Connective tissue mast cells were topographically and quantitatively studied in the newly formed lining tissue of six day old air pouches induced in the dorsal surface of mice. The results showed that the number of mast cells in the cavities innermost lining increased after injection of carrageenan into the cavity. Degranulation of mast cells was also observed. Variations in mast cell numbers in the lining seemed to correlate with the histamine content. These findings suggest that mast cells not only participate in the initiation of the early phase of acute inflammation but also appear to play an important part in regulating and prolonging more chronic inflammatory reactions.

Mast cells are found widely and randomly distributed in normal connective tissue. Their number has been observed to increase during connective tissue inflammation, ${ }^{1}$ and they are known to contain various biologically active substances such as histamine. ${ }^{2}$ Spector and Willoughby by determining the exudate histamine after intrapleural injection of turpentine concluded that the role of exudate histamine was to initiate and maintain the early vascular changes of acute inflammation. ${ }^{3}$ Mast cells are seen in the synovial lining of patients with arthritis, but the relevance of these cells remains unclear. In the present study we used the six day air pouch model ${ }^{4}$ to examine the response and the relative importance of these cells during inflammation in a synovial-like structure. It was hoped that this approach might give us more insight into the nature of the increased numbers of mast cells in the rheumatoid synovium. ${ }^{67}$

\section{Subjects and methods}

A N I M A L S

Male swiss mice weighing 20-25 g were used throughout the study. Six mice were used for each

Accepted for publication 19 March 1986.

Correspondence to Dr A D Sedgwick, Department of Pharmacology, The Royal Veterinary College, Hawkshead House. Hawkshead Lane, North Mymms, Hatfield. Herts AL9 TTA. experiment, which was repeated four times. Air cavities were produced by injecting $5 \mathrm{ml}$ of air into the subcutaneous tissue of the back of the animals. Three days later $2.5 \mathrm{ml}$ of air was injected into the same cavity to maintain its patency. Six days after the initial air injection animals were anaesthetised with ether and $1 \mathrm{ml}$ of carrageenan was injected into the cavity. Control animals were injected with physiological saline. Groups of animals were killed at $30 \mathrm{~min}$, and one, four, and 24 hours after the initial injection of the irritant. Total leucocyte numbers and the volume of fluid in the cavities were measured by the method previously described. ${ }^{8}$ The entire wall of the cavities was then removed, fixed in Bouin's fluid, and finally, embedded in paraffin wax. Serial sections were cut and stained with a modified Dominici ${ }^{9}$ and Csabas mast cell stain. Each section was microprojected on transparent paper at a magnification of $20 \times$. The margins of the cavity wall including hair follicles, muscles, and blood vessels were drawn. The mast cells were identified by their distinctive large cytoplasmic metachromatic granules stained with the toluidine blue of the Dominici stain and the Csabas mast cell stain. The location and number of mast cells were marked and counted. Mast cells containing distinct granules and nuclei were counted with an eye piece $12.5 \times$ and an objective $25 \times$. One hundred microscopic fields $\left(1.3 \mathrm{~cm}^{2}\right.$ each $)$ were counted. The histamine content 
of the pouch wall and exudate fluid was analysed by the method of Ronnberg and Hankanson. ${ }^{10}$ The significance of all data was analysed by Student's $t$ test.

\section{R R I T A N T}

Carrageenan (lot 272500) was kindly provided by Marine Colloid, Springfield, USA. A solution of $1 \%$ carrageenan in sterile physiological saline was left at $90^{\circ} \mathrm{C}$ for one hour until the mixture appeared homogeneous and clear.

\section{Results}

\section{NORMAL DISTRIBUTION OF MAST CELLS IN}

CAVITY LINING TISSUE

Fig. 1 shows the general profile of a six day old air pouch cavity. Since the injected carrageenan was found to form a sticky layer over the cavity lining adjacent to the body the wall of the cavity was divided into upper (UL) and lower (LL) wall for the mast cell study. In general the cavity was lined by a translucent layer consisting of collagenous fibres with elongated fibroblastic cells. This layer is referred to as the innermost lining of the air cavity. In between the fibroblastic cells were mononuclear phagocytes and a small number of polymorphonuclear cells. A few elongated mast cells were occasionally found scattered in this layer. In the upper wall a thin layer of skeletal muscle was seen in between the innermost lining and the dermis of the skin. Mast cells were seldom seen in this layer. Mast cells in the dermis were numerous and irregular in shape. They were found in the dense collagenous

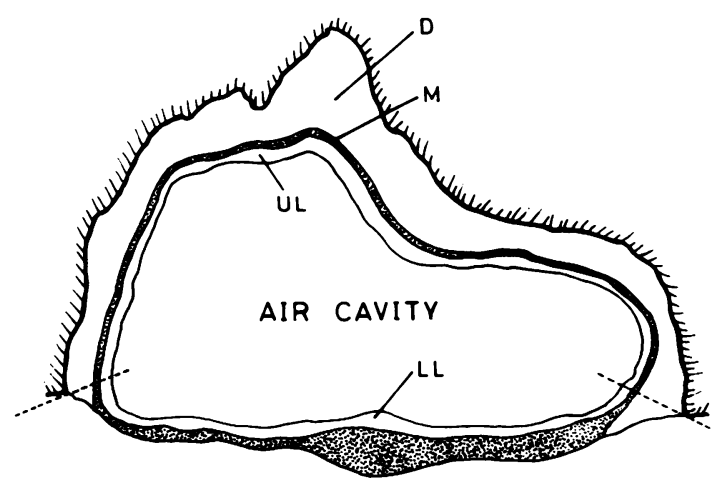

Fig. 1 General profile of a six day old air pouch cavity obtained from a three dimensional study. $D=$ dermis; $M=$ muscle layer; $U L=$ upper innermost lining; $L L=$ lower innermost lining. The two broken lines indicate the margin between the upper and lower innermost lining.
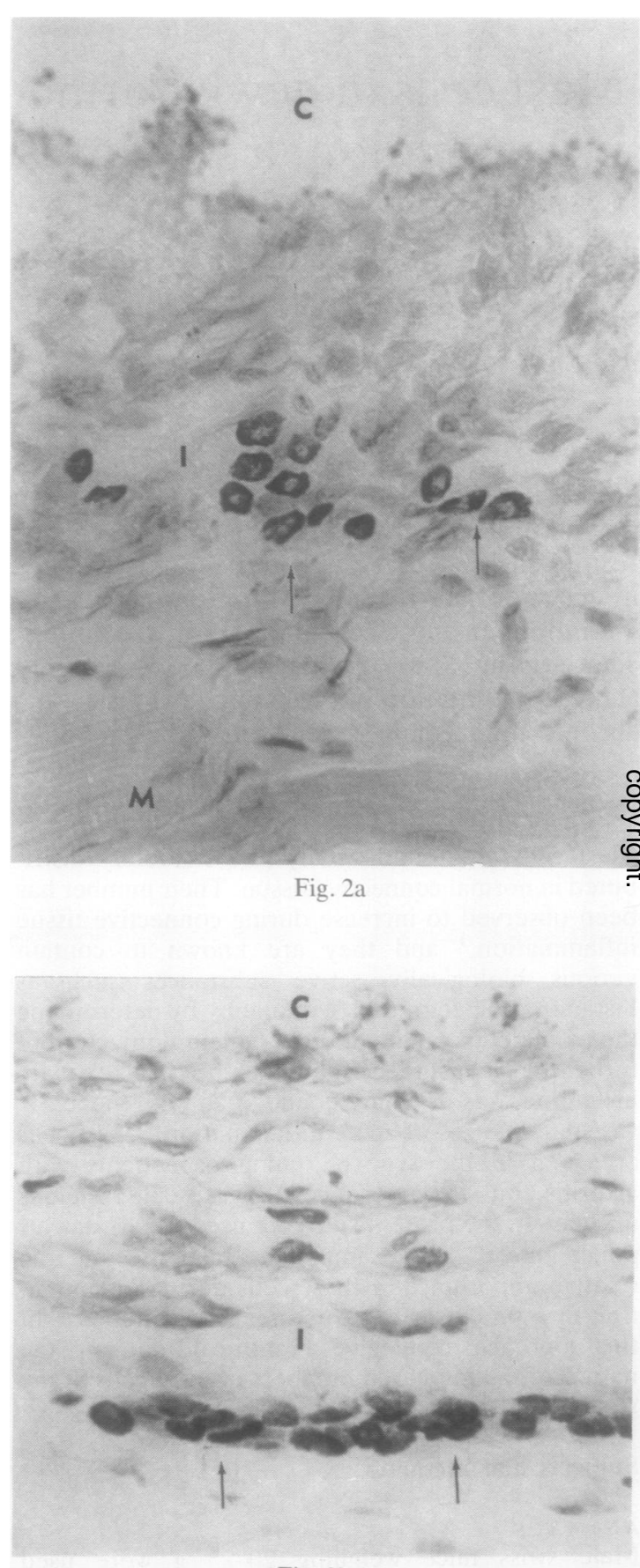

Fig. 2b

Fig. 2 Groupings of mast cells (arrows) in (a) the upper and $(b)$ the lower innermost lining of the air cavity at 30 minutes after the carrageenan injection into the cavity. $C=$ air cavity; $I=$ innermost lining; $M=$ muscle. 
fibres between hair follicles and concentrated more towards the epidermis.

A IR CAVITY IN JECTED WITH CARRAGEENAN Thirty minutes after the injection of carrageenan into the cavity, mast cells with irregular shapes were found in increased numbers in the cavity innermost lining. They were mostly distributed around blood vessels, particularly around the blood capillaries. Groups of mast cells appeared frequently, some consisting of more than 40 cells (Figs $2 \mathrm{a}$ and b).

Occasionally, a few mast cells were encountered at the margin between the cavity and the lining tissue. An increase in the number of mast cells was also found around the blood vessels in the dermis, particularly adjacent to the muscle layer. In this area the majority of mast cells were seen along the capillaries. Mast cells with considerably fewer granules than those of the control cavity lining were frequently encountered in the innermost lining (Fig. 3). Most of the mast cells in this lining were large and polyhedral with prominent pale nuclei.

The distribution of mast cells in various topographical regions appeared to be similar in the cavity wall at one, four, and 24 hours after the initial carrageenan injection. Groups of mast cells were seldom encountered. When present, the size of the group was relatively smaller, consisting of five to six cells in each group. Mast cells with few granules were also seen at one and four hours after carrageenan injection. Complete disruption of tissue mast cells was seldom seen throughout the time course studies.

Table 1 shows the mast cell counts in the various topographical regions of the cavity wall at several time intervals after carrageenan injection. The number of mast cells in the innermost lining increased at $30 \mathrm{~min}$ but significantly dropped $(p<0.05)$ at 60 min after injection. Thereafter their number gradually increased at four and 24 hour intervals. The number of mast cells in the lower innermost lining was two to three times higher than that in the upper innermost lining structure. It is interesting that the dermis, which was distant from the cavity, showed a similar increase in mast cells at one, four, and 24 hours after injection. Table 2 shows that an increased histamine content of the

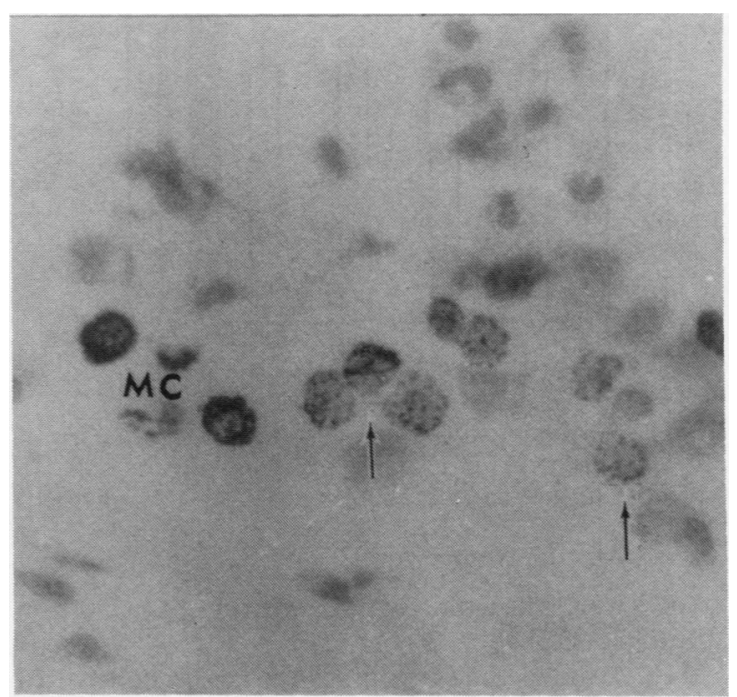

Fig. 3 A group of mast cells with few granules (arrows) in the innermost lining of the air cavity at 30 minutes after the carrageenan injection into the cavity. Note that there are two normal mast cells $(M C)$ with dense granules.

Table 2 Histamine content of pouch wall and exudate fluid at different time intervals after the carrageenan injection

\begin{tabular}{lcl}
\hline $\begin{array}{l}\text { Time after carrageenan } \\
\text { injection (min) }\end{array}$ & \multicolumn{2}{l}{$\begin{array}{l}\text { Histamine content } \\
\text { (mean }(S E))\end{array}$} \\
\cline { 2 - 3 } & $\begin{array}{l}\text { Exudate fluid } \\
(\mu g / m l)\end{array}$ & $\begin{array}{l}\text { Pouch wall } \\
(\mu g / g)\end{array}$ \\
\hline 0 & $1.46(0.23)$ & $121 \cdot 33(10 \cdot 97)$ \\
15 & $2.31(0.35)$ & $103.74(7.45)$ \\
30 & $10 \cdot 73(5.09)$ & $251.40(30 \cdot 18)$ \\
45 & $2.91(0.06)$ & $157.82(4.92)$ \\
60 & $1.05(0.12)$ & $165 \cdot 42(19.34)$ \\
75 & $3.46(0.81)$ & $149 \cdot 52(2 \cdot 12)$ \\
\hline
\end{tabular}

Table 1 Mast cell counts in different regions of the six day old air cavity wall after carrageenan injection

\begin{tabular}{|c|c|c|c|c|}
\hline \multirow{2}{*}{$\begin{array}{l}\text { Time after carrageenan } \\
\text { injection (hours) }\end{array}$} & \multicolumn{4}{|c|}{ No of mast cells (mean $(S E))^{*}$} \\
\hline & Dermis & Muscle & $\begin{array}{l}\text { Upper inner- } \\
\text { most lining }\end{array}$ & $\begin{array}{l}\text { Lower inner- } \\
\text { most lining }\end{array}$ \\
\hline $\begin{array}{l}\text { Control } \\
0 \cdot 5 \\
1 \\
4 \\
24\end{array}$ & $\begin{array}{l}286 \cdot 7(21 \cdot 6) \\
341 \cdot 4(8 \cdot 8) \\
547 \cdot 2(7 \cdot 6) \\
506 \cdot 6(21 \cdot 1) \\
486 \cdot 0(20 \cdot 2)\end{array}$ & $\begin{array}{rr}6 \cdot 3 & (1 \cdot 5) \\
3 \cdot 0 & (1 \cdot 5) \\
15 \cdot 4 & (2 \cdot 7) \\
8 \cdot 8 & (1 \cdot 7) \\
36 \cdot 2 & (7 \cdot 6)\end{array}$ & $\begin{array}{l}24 \cdot 3(2 \cdot 1) \\
54 \cdot 2(5 \cdot 0) \\
24 \cdot 1(5 \cdot 0) \\
41 \cdot 4(6 \cdot 3) \\
34 \cdot 0(4 \cdot 5)\end{array}$ & $\begin{aligned} 24 \cdot 1 & (0 \cdot 6) \\
187.2 & (13 \cdot 9) \\
60.0 & (3.8) \\
83.6 & (7 \cdot 7) \\
92.0 & (3.3)\end{aligned}$ \\
\hline
\end{tabular}

${ }^{*}$ Counted in 100 microscopic fields $\left(1.3 \mathrm{~cm}^{2}\right.$ each $)$. 
876 Sin, Sedgwick, Chea, Willoughby

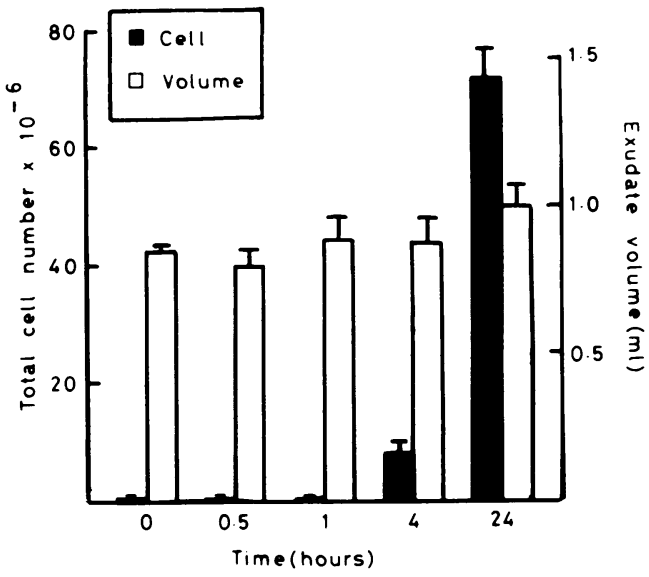

Fig. 4 The inflammatory reactivity of exudate in the six day old air cavity at different time intervals after carrageenan injection.

pouch wall and exudate fluid was found at $30 \mathrm{~min}$ after injection.

Fig. 4 shows the response both in the number of cells and the volume of exudate accumulating in the air cavity, at various time intervals after injection. The total cell numbers in the exudate were relatively low at 30 and 60 minutes after injection but were significantly increased $(p<0.05)$ at four and 24 hour time intervals. On the other hand, the exudate volume appeared to be relatively similar, though there were slight increases with time at the intervals studied. The values given for the volumes include 1 $\mathrm{ml}$ of heparinised saline used to wash out the cavity.

\section{Discussion}

The role of mast cells in connective tissue during acute inflammation is not clearly understood. ${ }^{3} 11$ 12 The connective tissue mast cells are different from mucosal mast cells because they are not only larger, with many uniform granules, but also have a higher histamine content.$^{13}$ In 1971 Mariano and Araujo showed that in rats, for the first two hours after intrapleural injection of turpentine, the number of intact diaphragmatic mast cells fell linearly with time. ${ }^{14}$ They concluded that this fall in the intact mast cell numbers was probably due to the progressive mast cell degranulation. This at least indicates that mast cells in the cavity lining are involved in the early phase of the acute inflammation induced by turpentine.

It has been shown that there is an increase in mast cells in the synovial membrane of patients with rheumatoid arthritis. ${ }^{67}$ Furthermore, an increase in mast cell numbers is seen in the perisynovial and periarticular tissue of early rat adjuvant arthritis. ${ }^{15}$ Their presence in the synovial membrane at the cartilage-pannus junction of rheumatoid joints is $\overrightarrow{\vec{m}}$ believed to play an important part in the pathophysiology of joint destruction in rheumatoid arthritis. ${ }^{16}$ Although mast cells were frequently encountered in the rheumatoid synovium, we have little information about them, particularly their relation to the initiation and intensity of acute inflammation. The present topographical and quantitative studies of $\vec{\circ}$ mast cells in the various regions of the synovial-like air cavity wall show a difference in their response $\omega$ compared with that shown by the diaphragmatic mast cells in pleurisy. as described by Mariano and 0 Araujo, ${ }^{14}$ in the following ways. Firstly, the number of of mast cells in the cavity innermost lining rapidly $\overrightarrow{0}$ increased at 30 minutes after the carrageenan $\infty$ injection. Thereafter, their number fell significantly w at one hour and then rose slowly at four and 24 hour 윽 intervals. Secondly, only mast cells with an unusually small number of cytoplasmic granules were $\bigcirc$ found in the innermost lining. Finally, an increase in ${ }_{0}$ histamine content was found at 30 minutes after $\underset{\Phi}{\mathbb{D}}$ carrageenan injection. All these findings indicate that mast cells are involved in the initiation of ear $\varnothing$ acute inflammation in a cavity lined by a synovi like structure.

It is interesting that the number of mast cells $\mathrm{m}$ the lower innermost lining of the cavity was two and three times greater than that of the upper innermost lining at various intervals after the carrageenan $\stackrel{\mathbb{Q}}{\mathscr{Q}}$ injection into the air cavity (Table 1). This differ- $\overrightarrow{\vec{A}}$ ence is possibly due to the effect of the injected $\frac{3}{3}$ carrageenan settling on the surface of the lower $\vec{P}$ innermost lining. Therefore, the observations might suggest that the number of mast cells in the lining tissue is dependent on the local concentration of $\overline{0}$ irritant.

In comparison with control animals the mast cells

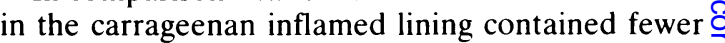
granules, suggesting that they were in the process of degranulation. It is possible that the carrageenan $\frac{\text { o }}{\partial}$ induces this process. The frequent degranulation of $D$ mast cells found at 30 and 60 minutes and the sharp을 decrease in mast cell numbers in the innermost $N$ lining at one hour after carrageenan injection indicate that these cells might release various 0 biologically active vasoactive amines or products of $\tilde{\omega}$ arachidonic acid which may initiate the acute inflammation. Cell accumulation and exudate forma-co tion, however, could not be correlated with the degree of mast cell degranulation. These findings $\stackrel{\oplus}{+}$ differ from those of Mariano and Araujo, who $\square$ showed that a decrease in intact mast cells in the diaphragm corresponded to the rapid increase of $\mathbb{Q}^{\mathbb{D}}$ 
exudate volume at two hours after injection of turpentine into the pleural cavity. ${ }^{14}$ Our results do to some extent support the work of Capasso et al, who showed that exudate histamine reached its highest concentration one hour after intrapleural carraageenan. ${ }^{17}$ Since the majority of mast cells were found closely associated with blood vessels one may suggest that the degranulation of mast cells in the early time intervals after carrageenan injection is initiating the vascular changes associated with the inflammation. Furthermore, the gradual increase in mast cell numbers in the cavity wall may be contributing to the continued pathological process.

To conclude, our results indicate that connective tissue mast cells may be involved in controlling and maintaining inflammation in a synovial-like structure.

The authors would like to thank the National University of Singapore and the Arthritis and Rheumatism Council for their support. We would also like to thank Mr H K Yip for photographic assistance.

\section{References}

1 Lewis R A, Austen K F. Mediation of local homeostasis and inflammation by leukotrienes and other mast cell-dependent compounds. Nature 1981; 293: 103-8.

2 Thon I L, Uvnas B. Degranulation and histamine release, two consecutive steps in the response of rat mast cells to compound 48/80. Acta Physiol Scand 1967; 71: 303-15.

3 Spector W G, Willoughby D A. Vasoactive amines in acute inflammation. Ann NY Acad Sci 1964; 116: 839-46.
4 Edwards J C W, Sedgwick A D, Willoughby D A. The formation of a structure with the features of synovial lining by subcutaneous injection of air. An in-vivo tissue culture system. J Pathol 1981; 134: 147-56.

5 Sin Y M, Sedgwick A D, Moore A, Willoughby D A. Studies on the clearance of calcium pyrophosphate crystals from facsimile synovium. Ann Rheum Dis 1984; 43: 487-92.

6 Hirohata K, Kobayashi I. Fine structure of the synovial tissue in rheumatoid arthritis. Kobe J Med Sci 1964; 10: 195-225.

7 Crisp A J, Chapman C M, Kirkham S E, Schiller A L, Krane S M. Articular mastocytosis in rheumatoid arthritis. Arthritis Rheum 1984; 27: 845-51.

8 Sin Y M, Sedgwick A D, Willoughby D A. Studies on the mechanism of cartilage degradation. $J$ Pathol 1984; 142: 23-30.

9 Sin Y M. Histological and topographical studies of germinal centres of rabbit lymph nodes. Br J Anat 1972; 112: 151-63.

10 Ronnberg A L, Hankanson R. A simplified procedure for the fluorometric determination of histamine in rat stomach. Agents Actions 1984; 14: 195-9.

11 Horakova Z, Bayer B M, Almeida A P, Beaven M A. Evidence that histamine does not participate in carrageenan-induced pleurisy in rat. Eur J Pharmacol 1980; 62: 17-25.

12 Wasserman $\mathrm{S} I$. The mast cell and synovial inflammation. Arthritis Rheum 1984; 27: 841-4.

13 Enerback L, Wingren U. Mast cells characteristics. Turnover of histamine in mucosal and connective mast cells of rats. Agents Actions 1984; 14: 358-60.

14 Mariano M, Araujo V C. Relation between diaphragmatic mast cell activity and exudate formation in acute experimental pleurisy. J Pathol 1971; 104: 275-81.

15 Gryfe A, Sanders P M, Gardner D L. The mast cell in early rat adjuvant arthritis. Ann Rheum Dis 1971; 30: 24-30.

16 Bromley M, Fisher W D, Woolley D E. Mast cells at sites of cartilage erosion in the rheumatoid joint. Ann Rheum Dis 1984; 43: 76-9.

17 Capasso F, Dunn C J, Yamamato S, Willoughby D A, Giroud $J$ P. Further studies on carrageenan-induced pleurisy in rats. $J$ Pathol 1975; 116: 117-24. 